\title{
Diphtheria in the former Soviet Union: The epidemic continues
}

The resurgence of communicable diseases in the countries of the former Soviet Union is one of the major issues on the agenda of the WHO's annual Regional Committee meeting for Europe (Athens, Greece, 6-10 September 1993). It is feared that the outbreak of diphtheria in Russia, with 4685 cases and 106 deaths during the seven months of 1993, and Ukraine, with 1462 cases and 41 deaths for the same period of time, might only be the beginning of a major epidemic. Diphtheria has been successfully controlled in developed countries for several decades. The widespread immunization of infants and children with diphteria toxoid vaccines introduced in 1940s and 1950 s resulted in a considerable reduction of diphtheria cases worldwide. In Europe the lowest level - 623 cases - was recorded in 1980. Some European countries have not reported a single case for more than ten years. Similar trends have been observed in Australia, Canada, Japan and the United States of America. In developing countries, diphtheria does not figure among major public health concerns. It is believed that skin infection with diphtheria bacteria provides protection against far more dangerous throat and laryngeal forms of the disease.

The incidence of diphtheria began to increase in the Soviet Union in the early 1980s. It reached its first peak in 1983-1985, when $1400-$ 1600 cases were reported annually. At the time, the number of cases of diphtheria recorded in the USSR constituted up to $87 \%$ of all diphtheria cases in Europe, as compared to $14 \%$ in 1974 . The second wave of the epidemic started in 1990

In Russia alone, 1896 cases and 80 deaths were reported in 1991. In 1992, those figures rose to 3897 and 125 respectively. In the first seven months of 1993, 4685 cases were recorded in Russia and 1462 in Ukraine. The highest incidence rates, ranging from 8.7 to 17 per 100000 population, were observed in the St. Petersburg, Kaliningrad and Orlovskaja regions as well as in Moscow. Although the majority of cases were reported among adults, the incidence rate was also very high in preschool and school children. Among the groups at greatest risk are food handlers, transport workers (railway stations and airports) and military and medical personnel.

The epidemic is still growing. During the month of July 1993, there were 983 new cases registered in Russia.

Ukraine has not been spared. Reported diphtheria cases rose from 1101 in 1991 to 1553 in 1992. In the first seven months of 1993 there were 1462 registered cases. The most affected areas are Kiev, the Crimea and Kharkov regions.
The reasons for the resurgence of diphtheria in Russia and Ukraine are complex. Three contributing factors have been identified: low and decreasing immunization coverage rates among infants and children, the weakening of immunity among adults, and a large movement of people during the last few years that could have contributed to the spread of virulent forms of the infection in the two countries.

The diphtheria outbreak in Russia and Ukraine has reached epidemic proportions. Measures undertaken by the local public health organizations have thus far proved insufficient. Health authorities in both Russia and Ukraine are now launching large-scale immunization activities in order to boost immunization coverage among infants, children and adults, especially those in high risk groups. There are clear signs that the epidemic is spreading to neighbouring countries. In 1993, Azerbaijan reported 28 cases, Belarus - 51 cases, Kazakhstan -23 cases, Uzbekistan -25 cases. Poland registered five cases of diphtheria stemming from Ukraine and Belarus. A 43-years old Finn contracted the disease in April 1993 while in St Petersburg the fist case of diphtheria in Finland for the last 30 years.

World Health Organization, Geneva 